\title{
Concepts For Managing In Turbulent Times: Received Wisdom From Dr. Deming
}

Goski Alabi, Institute of Professional Studies (IPS), Ghana

\begin{abstract}
This paper reflects on management in situations of variation, uncertainty and change in relation to using views and concepts from Deming's Systems of Profound Knowledge and his book "Out of the Crisis". The paper focuses on crisis-like events not generally associated with normal operations, otherwise called new realities. In doing this, the paper relates concepts from Deming's Systems of Profound Knowledge and views from Drucker and Dewey. The paper induces concepts for managing effectively in turbulent times and relates this to the Tylenol case of 1986. Logically inductive inferences resulting in a conceptual model are developed for effective management in turbulent time's using an analytical-conceptual methodology. The model proposes that in turbulent times, leaders should adopt a learning management approach, which includes understanding variation, communicating effectively and timely, cooperation, and adaptation, leading by given hope and direction and focusing on the customer, not the figures.
\end{abstract}

Keywords: Management; Turbulent Times; Variations; System of Profound Knowledge

\section{INTRODUCTION}

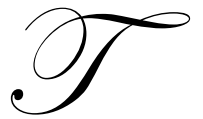

oday, managers all over the world are contending with rapid change and uncertainty and have to respond to both direct and indirect unprecedented turbulence in the global markets. Increasing competition, declining productivity growth, explosive technological change, erratic political and environmental change, and dissolution of market and national boundaries are familiar problems that threaten traditional organizational structures and management practices (Maller 2011, Holmes 2007). Crises are unpredictable events that can impact on an organization's viability, credibility and reputation (Baker, 2001; Mitroff, Shrivastava, \& Udwadia, 1987). They are a prominent feature of the business environment with the potential to damage any organization (Baker, 2001; Mitroff \& Alpasian, 2003; Pauchant \& Mitroff, 1992; Williams \& Olaniran, 2001). One of the functions of managers is to make decisions. The decisions are often based on interpretation of patterns of variations in figures, trends in observations and theories in use (Nolan and Provost 1990; Argyris and Schon, 1978).

Under the contemporary circumstances of rapid change, it is widely argued that organizations must change more rapidly than ever before. However, in making decisions for the future, uncertainty clouds people's vision and can create great disruption of plans. Operations suffer when people become emotionally distracted in their anxiety stirred by fear, uncertainty, doubt, grief, guilt and anger (Maller 2011, Holmes 2007). In the past decade, the world has experienced several emergencies - a Tsunami, hurricanes Katrina and Theresa, a credit crunch, a major recession, and now several political uprisings (Egypt, Lybya, Yemen, Syria among others), all of which have had their implications for management. The question is, "How do managers respond to such uncertainties, rapid change and variations?" An article published in The McKinsey Quarterly (2007 Number 2) by Anthony Holmes summed it up best: "Strategic-minded executives may not be able to control the "weather," but they can design a ship and equip it with a crew that can navigate the ocean under all weather conditions." A crisis need not strike a company purely as a result of its own negligence or misadventure. Often, a situation is created which cannot be blamed on the company, but the company finds out pretty quickly that it takes a huge amount of blame if it fumbles the ball in its response and the damage that can be done if they are not well-prepared (McKinsey, 2007, pg. 4). 
Managers who have the skills to negotiate such uncertainties can win the race regardless of the conditions. Holmes (2007) observes that an organization's success will only be as good as management's ability to decode the rising tide of complexity and its workforce's ability to execute the plan, but also the ability to turn such uncertain obstacles into opportunities for growth (Holmes, 2007).

This paper examines views of Deming on managing variations which are considered to include turbulent times in line with Drucker's description of turbulent times as 'new realities' (Drucker, 1993). It attempts to compare some aspects of the concepts recommended by Deming to that of Drucker and finally does an appreciative enquiry of Deming's views, drawing on this for a conceptual framework for managing in turbulent times.

\section{Deming's Perspective of Management as Prediction Versus Drucker's View on Management and Prediction}

Martinez (2008) notes, "Time is the basic dimension in which the work of all managers takes place" and Deming notes, "Management is not playing games; management is prediction" (1994, pg 101). Deming explains that the theory of knowledge teaches that management, in any form, is prediction", that knowledge is built upon theory, and rational prediction requires theory and builds knowledge through systematic revision and comparison of theory based on comparison of prediction with observation" (pg. 102). The question that arises from this quotation is, "What happens when circumstances throw a manager's prediction overboard? Will there be no management in that instance?" Drucker (1993) notes, "Long-term planning is necessary, precisely because we are unable to make predictions" in Martinez (2008). Deming, however, notes that every concept to be better understood should be placed in context or given an operational definition. In this context, Deming might have described management of prediction from the point of the planning function in management. Drucker, a pioneer of modern management thinking, warns, "Predicting can only get you into trouble" and states that the task of management is to manage what there is and work to create what must and should be. Executives are not in control of the universe anymore than mortals are" (1993). Does Drucker, in this context, suggest that prediction is not required in management? Drucker notes that managers live in the present, analyzing and making decisions today, but must, at the same time, focus on the future since the results of their decisions will become apparent tomorrow, thus the need to predict. As a result, managers must always take the future into account when making decisions, which supports Deming's view of "management as a form of prediction". Consequently, the purpose of management is to create value to meet expectations of stakeholders which requires a predictive function that takes place within a context that is defined by time. How can a manager balance and reconcile these three functions while taking time into account? Martinez (2008) notes that Drucker believed that management has to act like an orchestra conductor, who is also the composer of the work being performed, and be able to select the best from the resources available to them especially people - neutralize their weaknesses, and act in two dimensions of time - the present and the future. Parker, in Beaver \& Parker (1995), observes that before the 1980s, many companies rendered crisis management as "...something to be minimized or avoided...". This ignorant approach was exposed in the 1980s and early 1990s when many organizations were hit with cruel crises that crippled business operation. Since then, the objective of risk management, as financial organizations prefer to call it, has been significantly redefined.

Consequently, crisis management planning is a prudent way to minimize or eliminate the impact of a disaster on an organization. Much of the crisis management literature has addressed the for-profit sector. However, non-profit organizations (NPOs) must also plan for the unthinkable. Spillan, Crandall, and William (2002) note that the essence of crisis management is to plan for worst case scenarios and then seek to manage the crisis in the best manner should it occur. Further, Spillan, Crandall, and William (2002) ask, "But why have a plan to begin with when even the crisis management literature acknowledges that, by their nature, crisis events have a small chance of occurring?" (Barton, 1993; Pearson Fd Clair, 1998; and Shrivastava, Mitroff, Miller \& Miglani, 1988). Yet, a recent survey of Fortune 500 industrial companies revealed that 78 percent of these organizations had a crisis management plan in place (Penrose, 2000). What motivates decision makers to plan for events that are not likely to happen? What happens when a crisis that is not in the plan occurs? How should managers handle it? This paper seeks to find some clues from these questions from Deming's System of Profound Knowledge.

A reflection on the views of Deming and Dewey on the theory of knowledge and the quest for certainty, reveals that knowledge indeed has a temporal spread and whatever is known at any given time can only provide insurance, but not full assurance, about a fact or truth or the certainty of what is known or the future. According to 
Dewey (1930), an entity whose sole goal is to avoid errors will quite naturally be a total skeptic and assert nothing. The question, then, is not what propositions are certain, but what propositions might be preferable on the basis of our actions. The concept of strategic planning is already evolving as the realities of uncertainty and rapid change are telling on the concept of long-range strategic plans, which are thrown off with a little turbulence or change in the business environment. Long-range strategic planning is already giving way to shorter range planning, though with a focus on the constancy of purpose. According to Dr. Deming, the aim of a manager should be to maximize the system (Deming, 1993). However, Deming stresses that the system cannot be optimized without an understanding of variation and uncertainties. This calls for the use of theories and skills that can minimize the adverse effects of variations, uncertainty, and rapid change, bearing in mind that what is known is limited by the "knowable", the unknown, and the unknowable.

\section{Defining Management in Turbulent Times}

Management in turbulent times refers to what managers do in times of rapid change or variation, or when in difficulty or crisis situation. According to Drucker (1993), managing in turbulent times refers to how managers deal with new realities. How do managers surmount obstacles in turbulent times and still maintain focus on the constancy of purpose as proposed by Deming in his "14 Principles of Effective Management"? Crises are panic situations when people fret and are likely to act on impulse. In turbulent times, Drucker suggests that what managers require is "action rather than understanding, with decisions rather than analysis (Drucker, 1993). Drucker adds, "and in turbulent times, the first task of management is to make sure of the organization's capacity for survival, to make sure of structural strength and soundness of its capacity to survive a blow, to adapt to sudden change, and to avail itself for new opportunities" (Drucker, 1993, pg. 3). Subsequently, Drucker adds, "Any attempt to manage in turbulent times must start with the most predictable of all developments" (1993, pg. 4). On the other hand, Deming suggests a reflective in-action approach. Deming says, "in times of variation or crisis, do not 'tamper' with the system or process, but rather try to gain an understanding of what is happening before you attempt to run from the fire, lest you get into the furnace." Deming describes tampering as action on the system without action on the fundamental cause of the trouble. This is because actions taken in 'tampering' only seek to address symptoms, not root causes. The Tylenol cases of 1983 and 1986 are typical examples of the reappearance of a crisis because the cause of the 1983 fire was not well understood to be stamped out. In the case of the 1986 Tylenol crisis, an understanding of the root cause led to the development of a tamper proof seal to forestall reoccurrence. Deming adds that the fundamental cause of the trouble is failure of people to understand what is best..." (Deming, 1993, p. 67). According to Dr. Deming, when people do not understand the system and they tamper with a stable system, they make things worse (pg. 173), stating "The results of tampering is only to increase future mistakes ...the opposite of what we wish to achieve". In line with Deming's view on managing variation and turbulence, African wisdom teaches "Why uproot the thorns while still in the thorns'? Combining the wisdom of Deming and Drucker, the paper analyzes views of Deming for managing in turbulent times and draws on lessons from the Tylenol case. However, on combining Deming and Drucker's views, one question lingers - "How soon should managers act or not act while trying to understand the system?" Obviously, acting without understanding of the system could result in more crises. However, waiting too long to understand the cause of the crisis before acting could also be detrimental. The questions, then, are, "How long should it take to understand the system before acting? How can the pitfalls of both approaches be avoided?" The focus of this paper is to draw from the wisdom of Deming's System of Profound Knowledge on managing in turbulent times.

\section{Change, Variation and Uncertainty - Implications for Management Functions Theory}

The quest about 'what knowledge is' remains unresolved. How do we know that something will or will not happen and how much knowledge do we have to act in surety at any time? What are the implications of what we perceive to know on management practice and theory?

The reflections in this session are based on extracts from a dialogue between the Caterpillar and Alice in the book "Through the Looking Glass" where the caterpillar asked Alice, "Who are you?" Alice replied rather shyly, "I-I hardly know sir at present; at least I know who I was when I got up this morning, but I think I must have changed several times since then." (Lewis Carroll, 1872, p. 60). In "Alice's Adventure in Wonderland", it is quoted "How puzzling all these changes are! I am never sure of what I am going to be from one minute to another! (Lewis 
Carroll, 1898, p. 74). This dialogue illustrates the degree of uncertainty under which people, including managers, act and make decisions for the future as they make predictions based on past experiences or theory, plan, strategize, organize and deploy their strategies. Why do managers, plan, strategize, communicate their plans, organize required resources, plan for risk management, deploy plans, manage performance, monitor systems, evaluate systems and yet sometimes fail? Is managing in uncertainty, variation and change a case of exception or a subject of circumstance that does not require routine attention? What is Deming's answer to this question? Why are some managers unable to deal with variations and uncertainty effectively in everyday management?

Using a conceptual inductive methodology, the author sought to infer from works of Edwards W. Deming. Deming is generally considered the father of Total Quality Management. However, a latent view of the author is that most of Deming's views seek to address issues of effective management, particularly in times of variation. The author therefore opines that Deming could also be considered an icon of effective management theory, particularly in times of uncertainty or variations.

In his books, "The New Economics for Industry Government and Education" (1994) and "Out of the Crisis", Deming presents his concepts of the "System of Profound Knowledge", which the author considers a philosophical foundation for Deming's 14 points of management and the seven deadly diseases of management (Deming, 1986). What had not been clearly associated with Deming are his views on managing in rapidly changing times and in situations of variations. The objective of this paper is to identify and examine how Deming suggests managers could handle rapid change and variation. The aim is to use these two view points to draw some inferences on contemporary management theory and practice, particularly management in situations of variation and uncertainty, which are inevitably routine situations in everyday management of an organization.

\section{OBJECTIVE AND FOCUS}

The objective of this paper is to identify concepts for managing in turbulent times from Deming's System of Profound Knowledge and other concepts from his book "Out of the Crisis".

The paper focuses on: 1) crisis-like events not generally associated with normal operations of the organization and therefore does not delve into the four different and distinct phases of crisis management, which include the prodromal crisis stage, acute crisis stage, chronic crisis stage, and crisis resolution stage (Fink, 1986; Barton, 1993; Mitroff, 1996; and Fearn-Banks) and 2) how managers should handle new realities given the uncertainty of what is known at any given time. How should managers respond to turbulent times or times of variations or new realities? How can managers provide insurance for their actions in rapid change and in the face of new realities? The paper sets out some proposals for responding to new realities using Deming's System of Profound Knowledge and the Tylenol case.

\section{ASSUMPTIONS}

This paper assumes that many managers perceive uncertainty and risk as remote occurrences which require reaction as and when they occur and that managers, who plan for risk approach, risk management and uncertainty as either assurance or insurance.

\section{METHODOLOGY}

The paper employs a conceptual development phase of theory building approach for single or multiparadigm research. The four methods selected for this review are: 1) Weick's method of "theorizing as disciplined imagination" (1989); 2) Whetten's method of "modeling as theorizing" (2002); 3) Chermack's method of "scenario planning as theorizing" (2006); and 4) Storberg-Walker's method of "five components of conceptual development" (2007b) as described by Storberg and Chermack (2007). Using aspects of these methods, the paper reviews Deming's Systems of Profound Knowledge and other concepts in his books "The New Economics for Industry, Governments, Education" (1993) and "Out Of The Crisis" (1987) to identify views for managing in rapid change crisis-like events not generally associated with normal operations. The paper then relates and compares these elements to views from other management experts to establish a model or framework for managing in turbulent 
times as it draws on the Johnson and Johnson Tylenol case of 1986. Howell \& Miller (2006) note that crises that have received extensive mass media coverage include the nuclear accidents at Chernobyl and Three Mile Island, the Exxon Valdez oil spill, Tylenol pain relief package tampering, Dow Corning breast implant litigation, the collapse of Enron, and the James Hardie Industries' asbestos case. This formed the basis for choosing the Tylenol case for the reflections in this paper.

\section{An Exposé of Deming's System of Profound Knowledge}

The System of Profound Knowledge has four key elements; namely, the systems thinking, understanding variations, using the theory of knowledge and using psychology. The four component parts of the System of Profound Knowledge all emphasize the importance of the system and how to optimize it. Deming notes that the purpose of the System of Profound Knowledge is to provide clues by which the style of management can undergo transformation. According to Deming, "understanding of the profound knowledge can lead to transformation of management. The transformation will lead to adoption of what we have learned to call a system with a stated aim. The individual system, instead of being competitive, will, for optimization, re-enforce each other" (Deming, 1994, Pg. 116). What is required in turbulent times is a focus on the problem, not competition, which will require cooperation.

\section{Understanding Variation}

Variation can be defined as "deviation from the norm or from the expected outcome". It can be described as a lack of uniformity or fluctuation, and as the difference between one event and another. Variation, in any form, causes inconsistencies, making it the main contributor to increased uncertainty. Mismanagement of variation allows uncertainty to determine outcomes (Deming, pg. 123).

However, to optimize the system, variation is to be seen as a part of life and we must be ready to deal with it as one would deal with a routine activity that is planned for, or to be dealt with each time it occurs. The physiological readiness to deal with variation as a routine activity is key to handling turbulence effectively. This psychological state may be required to keep the manager from fret or panic situation in turbulent times because crisis management has been considered a key part of risk management interventions. This psychological state may allow the manager to seek an understanding of the causes and sources of variations whenever they occur so that they are handled effectively. Additionally, it is important to recognize that variations can be controllable when they occur in resources, such as inputs or processes, but uncontrollable when they come from external uncontrollable sources, like changes in the times and seasons, or other unforeseen environmental conditions, the credit crunch and unexpected economic recessions, new policies and regulatory frameworks and disasters, which are beyond the limits of the entity, be it an individual or organization. In all these cases, an understanding of the causes and nature of the variation can help to mitigate or contain the situation and/or optimize the system. Variations, however, from the author's perspective, can be systemic, external or structural. Systemic variations could be of common or special causes. Common cause variations are often inherent in a process and may require a complete overhaul or reexamination of the process to remove them. They are often recurrent and chronic and the variations may not be so different from each other. Special cause variations, on the other hand, are variations resulting from an assignable cause. Special cause variations are sporadic and sometimes emergencies which may require immediate attention to bring the process back on track. In cases of crisis situations, special causes can be beneficial, in which case the cause is identified, rectified and incorporated in the standard practice. In some cases when well handled, this could also lead to improvement in the system. However, external variations could often be considered as a noise factor, which cannot often be removed but can be managed with the aim of reducing their effect on the system. Turbulent times may often be of external uncontrollable sources and, in such cases, become special cause variations which may require reflective but timely attention. Structural variations are varying trends within the data. They often take the form of seasonal variation and growth or decline (where the data have, for example, an underlying trend of increasing 4\% annually). Deming notes, "Tampering, which is taking action based on the belief that a common cause is a special cause or vice versa, in itself could serve as a form of variation to the system. The tendency to take action without sound reason could cause more problems than it fixes." (Nolan and Provost, 1990) 


\section{Systems Thinking}

A system is a body or network of interdependent and interrelated parts that seek to fulfill an aim and, in the process, interacts continuously with the external environment in an open manner. Because every entity or organization depends on its component parts and the interaction with its environment for survival, the effective functioning of every organization or business entity will require systems thinking. Deming suggest here, though not explicit, that we all, whether as individual or organization, depend on other people for our survival. Deming emphasizes that the aim of the manager should be to optimize the system. To do so, it is important for managers to appreciate the influence of every unit and component of the system, as well as the influence of the operational environment on the output and outcomes of the organizational efforts (Deming, 1994, and Luning et al, 2002).

Systems thinking is the process of understanding how things influence one another within a whole in a given context. In practice, systems thinking is about being conscious of how various elements work together to enhance or undermine the achievement of a common purpose and acting with that consciousness. In organizations, systems consist of people, structures, culture, processes, and the context that work together to make an organization healthy or unhealthy. Systems thinking is not one thing, but a set of habits or practices within a framework that is based on the belief that the component parts of a system can best be understood in the context of relationships and interactions with each other and with other systems, rather than in isolation (Senge, 1990). Systems thinking concerns an understanding of a system by examining the linkages and interactions between the elements that compose the entirety of the system (Deming, 1994).

From Deming's perspective, systems thinking is the concept of looking at the bigger picture, the common good, and having the understanding that the sum of the individual parts is never equal to the resultant effect of the system. Therefore, to optimize the system, there is need to focus on the system as a whole and not just the individual parts. Both Peter Senge and Steven Covey, authors of Principles of Effective Organizations and Effective People, like Edward Deming, have documented the power of systems thinking in achieving effectiveness in both personal management and organizational management (Covey, 1989 and 2004, and Senge, 1990). Deming adds that "A system includes the future." Deming further explains that "managers and leaders have still another job; namely, to govern their own future not to be merely victims of circumstance". Additionally, Deming emphasizes that preparation for the future includes lifelong learning for employees and constant scanning of the environment (technical, social, economic) to perceive the need for innovation, new product, or innovation of service" (pg. 54). This may also involve media management and relationships (Flink, 1986).

In crisis or turbulent times, systems thinking comes in handy in analyzing various alternative actions or scenarios and the consequences on stakeholders within and outside of the organization and the relevance of each component part in overcoming the situation. The concept of systems thinking can facilitate ethical consideration, particularly from a utilitarian or consequential perspective, when dealing with new realities.

\section{Using the Theory of Knowledge}

In putting forward the use of the Theory of Knowledge, Deming seemed to suggest that one way to minimize the effects of variations is to use theory. Deming argues that without theory, there can be no prediction. Deming stressed, "Without theory, experience has no meaning, and without theory, one has no questions to ask. Hence, without theory, there is no learning. Theory is a window into the world. Theory leads to prediction, and without theory, experience and examples teach nothing" (Deming, 1994, p. 103). Deming further argues that "the theory of knowledge teaches us that a statement if it conveys knowledge, predicts future outcomes with the risk of being wrong, and it fits, without failure, observations of the past. Rational prediction requires theory and builds knowledge through systematic revision and extension of the theory based on comparison of prediction with observation." (Deming, 1994, pg. 102) On page 106, Deming adds, "Information, no matter how complete and speedy, is not knowledge. Knowledge comes from theory, and without theory, there is no way to use the information that comes to us on the instant."

The Quest for Certainty is a study of the Relation of Knowledge and Action and the difference between knowledge and belief in the context of how knowledge and belief can contribute to practical action. The premise of 
this theory is that knowledge and belief are not equal to certainty and uncertainty (Dewey, 1930). The question here is, "Can theory be separated from practice or knowledge from action?"

Dewey believes that philosophers have frequently been misled by the assumption that the difference between knowledge and belief is the same as the difference between certainty and uncertainty. Knowledge has often been assumed to be a state of certainty, while belief has been assumed to be a state of uncertainty. Permanent and logically necessary truths have been assumed to be possible objects of knowledge, while conditional or empirical truths have been assumed to be objects of belief. The question is, "to what extent do managers make use of permanent and necessary truths?" Deming (1994) posits that knowledge is not static and that knowledge has a temporal spread. Considering that variation is inevitable in life and that managers are always dealing with variations, then holding on to some perceived permanent truth, even when a change might be necessary, could mean a preparation for failure. Eric Hoffer (undated) states that in times of change, learners inherit the earth while the learned find themselves equipped to deal with a world that no longer exists.

The Quest for Certainty, says Dewey (1930), is an attempt to separate theory from practice and to separate knowledge from action. It may also be an attempt to unify the ideal and the real. The Quest for Certainty describes the way that humans have, throughout the ages of philosophy, sought after absolute notions by which one could make one's life more certain. Dewey argues that a lot of the problems within the theory of knowledge are created by the assumptions about the capacity of knowledge itself.

According to Dewey, knowledge is how we act on and how we interact with the empirical world. Knowledge is defined by practical action. Thought is not merely a property of intellect, says Dewey; it is an activity leading to practical action. Practical action depends on belief because beliefs are rules for action. The validity of beliefs depends on their consequences for action. Deming supported this view when he stated, "Without theory, experience has no meaning. Theory is a window into the world." (Deming, 1994, pg. 103) In turbulent times, managers should base their actions and inactions on both knowledge and belief, carefully considering the consequences of the various scenarios and actions. Theory, our understanding of the reality, should be a manager's window into the future in planning to manage risk. Eric Hoffer (undated) observes that "the remarkable thing is that it is the crowded life that is most easily remembered. A life full of turns, achievements, disappointments, surprises, and crises is a life full of landmarks. The empty life has even its few details blurred and cannot be remembered with certainty".

Use Psychology

According to Deming, psychology helps to understand people, interaction between people and circumstances, interaction between leaders and employees, and any system of management (pg. 108). People are different from one another and a manager of people must be aware of these differences. Since human behavior and decision-making can affect the determination of future outcomes, it becomes imperative to use psychology to optimize the system. The contemporary definition of management describes management as an interaction between people seeking to achieve a common goal. Management is therefore a human or relationship function where people work with or through people to accomplish both personal and organizational goals. This is why the use of psychology becomes imperative in optimizing the system.

\section{Deming Teaches on Knowledge of Variation}

According to Deming, "Life is Variation or Variation is life." (1993, pg. 207) "Variation there will always be, between people, in output, in service in product." (Deming, 1993, pg. 98) The concept of variation can be extended to cover variation in times, conditions, and circumstances.

Deming explains that life consists essentially of variations; therefore, it is important to understand the causes of variation to enable effective management. Deming asserts that no two objects, events or phenomena can be the same. From this perspective, variation is inevitable in life. Therefore, for a manager, what is important is to be aware that variations there will always be and to understand variations in the system whenever they occur in order to management them effectively. There are variations in all the resources that are managed. These resources include 
man, money, methods or processes, materials, machines, moments or the times, milieu or environment, information or messages, management systems, and the manners or culture which the author calls the ten management resources (10 Ms). Even though Deming's concept of understanding variation was essentially limited to variations in the process, as a principle, in this paper, variations are perceived to include variations in all management resources, including the people, information systems, structures, times or seasons, and the context or milieu. It is therefore important for a manager to make room to accommodate such variations when working with any kind of resources. This requires a mind set and an orientation that recognizes that variation is characteristic and inherent in nature and in systems and should be seen as an opportunity to create new responses, paradigms, and concepts which can result in improvements of products, processes, management systems and structures.

\section{Managing in Turbulent Times - Received Wisdom from Deming}

How does Deming suggest managers should respond to variation and by extension turbulence? According to Deming, there are two mistakes that managers sometimes make in times of variation or new realities, and both of them could be very costly:

Mistake 1 - to react to an outcome as if it came from a special cause when it actually came from a common cause variation

Mistake 2 - to treat an outcome as if it were a common cause variation when it actually came from a special cause

A process or system may be in statistical control or it may not be. In the state of statistical control, the variation expected is predictable. Cost, performance quality, and quantities are predictable under such conditions. Variations in a state of statistical control are of common cause nature and often inherent in a process or system. As a result, common cause variations often emanate from within an organization's internal system. Improvement of a common cause variation or a statistically stable system would require a fundamental change in the process (1993, pg. 202). However, special cause variations emanate from processes and systems that are or may not be statically stable. They normally blow over a system or process, and overcoming them restores the system to normal and may normally, though not always, not re-occur in a similar manner. However, even for a stable system, special cause variations can re-occur (pg. 203) if the condition causing the variation is not removed. A typical example is the Tylenol crisess of 1983 and 1986. Deming suggests that steps to forestall re-occurrence of a special cause of variation should be taken, except where the cost is outlandish (pgs. 203 and 216). However, variations in turbulent times, which Drucker termed "new reality", could be of internal or external origin. Turbulence or new realities, in this paper, are assumed to be of the nature of special cause variations and may be both of internal or external origin where the organization may have little control over them. In such cases, they may be considered as noise factors that cannot be ignored and, though little can be done about their causes, their effects can and should be managed (Dale, 1984). A typical example is the various responses to sudden environmental disasters like Tsunamis and hurricanes. Deming notes that the two mistakes managers make in handling variations or new realities are not only costly but could lead to calamity if not well handled (pg. 197). The author opines that turbulence is often of a special cause nature because it mostly emanates from systems external to the organization, though not always. However, Deming observes that some economic crises and recessions are of common causes (pgs. 176 and 216).

To handle variations or new realities, Deming suggests:

1. DO NOT TAMPER with the system or process because the result of tampering only makes mistakes in the future (pg. 202). Take time to gain understanding of the situation before you act. Do not remove the thorns whiles in the thorns. But, how much time should be taken to gain an understanding of the cause of variation? The answer is, reasonable time as the specific case may require. This requires sound judgment of the situation and time needed for action. Deming maintains that unfortunately, speed does not help anyone to understand the future and the obligations of management. Many of us deceive ourselves in the supposition that we need constant updating to cope with the rapidly changing future (pg. 106), but you cannot, by watching every moment of television or by reading every newspaper, acquire a glimpse of what the future holds (pg. 106). Deming maintains that information, no matter how complete and speedy, is not knowledge. 
2. LOOK FOR CLUES FROM WITHOUT. Deming emphasizes that "A system cannot understand itself". According to Deming, the System of Profound Knowledge comes from the outside. Deming adds that the people who work in an organization know what they are doing, but they will not, by themselves, learn a better way. Their best efforts and hard work only dig deeper the pit that they are working in. Their best efforts and hard work do not provide an outside view of the organization (pg. 123). Deming adds that transformation is required to move out of the present state, not a mere patchwork on the present state of management. We must, of course, solve problems and stamp out fires as they occur, but these activities do not change the process (Deming, 1994, pg. 123). Reflection on the system and planning is required for transformation.

3. THINK SYSTEMS. Look within and outside the box and understand the inter-relationships and interaction among the various components with a view of understanding consequences of various scenarios of action on the components both in the system and its environment.

4. LEAD BY USING PSYCHOLOGY TO COMMUNICATE EFFECTIVELY. In times of turbulence or variations, what management needs are people to reason with, not people to blame. Managers also need the cooperation of the people in times of new realities. According to Deming, a leader should have great ideas and great plans, and by implication, a leader in turbulent times would have to show the way and give directions using his ideas and plans. He must have the persuasive ability to be able to sell his plans to his members in distress and provide a sense of hope for them. How can the leader do this? First, inducing from Deming's position, a leader in turbulent times must be a strategic thinker. He must see light in darkness and opportunities in the boundaries of obstacles. He must be imaginative and think solutions rather than lament on the problem. Deming cautions that, in difficult times, when colleagues may not wax enthusiasm about a leader's ideas, the way to go is to focus on a presentation of a plan of action and that acceptance of great ideas depends on simplicity and brevity of presentation. The leader must think of an action plan in good time, while mindful of the potential catastrophic effect of 'tampering'. Why use psychology in this case? Deming maintains that "psychology helps us to understand people, interactions between people and circumstances, interactions between customers and suppliers, and between competitors ....and between manager and any system of management" (pg. 123).

Peter Senge argues that learning organizations require a new view of leadership. He sees the traditional view of leaders as special people who set the direction, make key decisions and energize the troops as deriving from a deeply individualistic and non-systemic world view (1990, pg. 340). At its centre, the traditional view of leadership 'is based on assumptions of people's powerlessness, their lack of personal vision and inability to master the forces of change, deficits which can be remedied only by a few great leaders' (op. cit.). Against this traditional view, he sets a 'new' view of leadership that centers on 'subtler and more important tasks'. In a learning organization, leaders are designers, stewards and teachers ${ }^{1}$. The new manager in turbulent times must be a steward and guide of his team.

5. COOPERATION RATHER THAN COMPETITION. Why compete when already in crisis? Crisis demands help from where help must come. Turbulent times are not times to look for people to blame or scapegoats; it is a time to focus on the new reality. Rothkopt (2011) notes about Japan's recent tragic combined effect of Tsunami and unprecedented earthquake, "What the images of disaster fail to adequately convey - unless you are looking for it - is that the very predictability of this disaster, combined with the industry, innovation, and character of the Japanese people, has dramatically reduced the toll of this mega disaster. No nation is better prepared for earthquakes or tsunamis, none has more exacting building codes, none spends more time drilling its citizens on how to respond to such crises, and none has a culture of cooperation and respect for the community that makes working together in the wake of such events more certain or effective."

Deming notes that one of the new roles of a manager, after transformation or encountering of a new reality, is to understand the benefits of cooperation and the losses from competition between people

${ }^{1}$ www.infed.org/leadership/traditional/leadership 
and between groups (Deming, 1994, pg.113, and Alfie Kohn, 1986). To illustrate this point, the author presents some lessons from a popular open market for vehicular spare parts in Accra, Ghan, called "Abbosey-Okine Market". Though anecdotal, the case of Abbosey-Okine may provide some insights. Traders in that market are perceived to be quite successful with a few notable business men in Ghana having had their beginnings there. What is special about Abbosey-Okine? Traders in Abosey-Okine understand the power of interdependence more than competition. When a customer needs an item and 'Store A' does not have it, all that Store A requires is a phone call to Store B to request the item for the customer. After that phone call, if Store B has the product in stock, it is not likely that Store B would sell that item to a customer if Store A has not come for the quantity requested. These traders have a coded language and this practice of cooperation is a norm at Abbosey-Okine. In a time of unusual inflation (2001) and economic instability in Ghana, this concept of cooperation was extended at Abbosey-Okine, where a number of traders come together to gather moneys to be able to raise enough funds to import directly from manufacturers, cutting off middle men and bringing down cost of items. This practice was carried on radio for some time to encourage other traders. This meant that they had a way to maintain strength and move on while many others folded up or crampled down. As a result of this cooperative system, traders at AbboseyOkine provided a cushion against the shocks of economic turbulence through shared risk so that the blows from the turbulent tides will not knock them off their enterprise. The lesson here is that turbulent times are times to cooperate, not a time to fight. Fighting the fire of turbulence on its own should be enough to capture the attention of an effective manager. It must, however, be noted that the argument here does not suggest that competition in itself must be avoided, which is not realistic. Quoting from Alfred Politz, "nothing can cause so much harm as a lousy competitor; be thankful for a good competitor".

6. LEARN BY USING THE THEORY OF KNOWLEDGE. According to Deming, "We are, today, in possession of instant communication with any part of the world. Unfortunately, speed does not help anyone to understand the future and the obligations of management" (pg. 106). Many of us deceive ourselves into the supposition that we need constant planning and updating to cope with the rapidly changing future; but you cannot, by watching every moment of television, by reading every newspaper, or undertaking analysis of potential threats and risk management plans, acquire a glimpse of what the future holds (pg. 106). Deming maintains that information, no matter how complete and speedy, is not knowledge. Knowledge comes from theory. Without theory, there is no way to use the information that comes to us on the instant. Rational prediction requires theory and builds knowledge through systematic revision and extension of theory based on comparison with prediction and observation. Thus, risk management interventions aimed at managing new realities should incorporate the concept learning from the theory of knowledge, knowing that what is known at any time is dwarfed by the unknown and the unknowable. Managers should build a higher quotient for adversity and be strategic in times of new realities.

7. ADAPT. Flexibility is required in everyday management. The mentality that anything could happen and change plans is very necessary for the preparedness to withstand change and uncertainty. This requires preparation for the unforeseen, a risk management focus, an alternative plan or plan B, or, in some cases, modification of plans when it becomes necessary.

8. FOCUS ON THE CUSTOMER, NOT ON MANAGEMENT BY RESULTS OR OBJECTIVE (MBR OR $\mathrm{MBO}$ ). In times of turbulence or variation from the expected, which forms the basis of new realities as described by Drucker, a risk management approach would be required. The risk mitigation strategy should be based on a utilitarian or consequential philosophy, considering the benefits and harms that may be caused to key stakeholders for any alternative actions, as possibly intended. Deming stresses that "The most important act that a manager can take is to understand what it is that is important to the individual". (pg. 123). There are two individuals in this case - the internal and external customers. Deming suggests that in times of variation and by extension turbulence, managers should first look within and provide feedback and support to staff who are the internal customers. During times of crisis or uncertainty, people could be frustrated without enough information. The manager's obligation is to calm down the tension by providing adequate information and communicating effectively to allay fears and provide hope. It is important to note the difference in provision of information, which is a one-way flow, and communication, which is dialogue between people and groups and a two-way flow. In turbulent times, the manager's role is to perform both 
provision of information and communication. Holmes (2007) recommends that in times of turbulence, managers should obtain multiple opinions in the decision-making process. Deming maintains that the obligation of an effective manager is to contribute its best to the system and not to maximize its own production, profit, sales, or any other competitive measure. Deming notes, "Best for everyone concerned should be the basis for negotiation between people, unions, customers, and countries and everyone wins." (pg. 169) In turbulent times, staff turnover is likely to be high which can affect quality and other mitigation strategies. One way to mitigate this is to provide hope and ensure high staff morale. A strategy team becomes immediately necessary to give direction.

Deming teaches that the customer is why we exist and the aim of management action should always be in the best interest of the customer. In times of crisis or turbulence, the focus of the manager should not be to maximize profits or increase productivity or targets; it should be the customer, the customer and the customer. By focusing on the external customer, the organization is likely to avoid cutting corners, which could reduce customer confidence and dent company reputation. During crisis, it also becomes necessary to give the external customer and the general public some information, so public relations activities ought to be heightened with the aim of communicating with the public. The Tylenol case and Tiger Woods' response to the recent crises both adapted a customer focus approach. This restored customer confidence and helped to surmount the problems.

\section{Lessons from the Tylenol Case of $1986^{2}$}

The Johnson \& Johnson response to the Tylenol poisoning is a classic case of how a company can get it right by focusing on the customer. In 1982, Johnson \& Johnson's Tylenol medication commanded 35 percent of the US over-the-counter analgesic market, representing something like 15 percent of the company's profits. During the fall of 1982, for reasons not known, a malevolent person or persons, presumably unknown, replaced Tylenol ExtraStrength capsules with cyanide-laced capsules, resealed the packages, and deposited them on the shelves of at least a half dozen or so pharmacies and food stores in the Chicago area. The poison capsules were purchased and seven unsuspecting people died a horrible death. Johnson \& Johnson, parent company of McNeil Consumer Products Company which makes Tylenol, suddenly, and with no warning, had to explain to the world why its trusted product was suddenly killing people (Berge, 1998). This was a typical case of a special cause variation re-occurring because the condition causing it had not been adequately addressed or removed to avoid reoccurrence.

When the same situation happened in 1986, the company had learned its lesson well. It acted quickly, though with some insights, ordering that Tylenol should be recalled from every outlet - not just those in the state where it had been tampered with. Not only that, but the company decided the product would not be re-established on the shelves until something had been done to provide better product protection. As a result, Johnson \& Johnson developed the tamper-proof packaging that would make it much more difficult for a similar incident to occur in the future.

\section{Primary Evidence}

Robert Andrews, Assistant Director for Public Relations at Johnson \& Johnson, recalls how the company reacted in the first days of the crisis: "We got a call from a Chicago news reporter. He told us that the medical examiner there had just given a press conference - people were dying from poisoned Tylenol. He wanted our comment. As it was the first knowledge we had here in this department, we told him we knew nothing about it. In that first call, we learned more from the reporter than he did from us." Andrew's dilemma points out something that has become more prevalent with the expansion of 24-hour electronic media. The media will often be the first on the scene, thus have information about the crisis before the organization does (Berge, 1990). However, Johnson and Johnson did not react to media dictated in a panic situation. Theirs was a reflective approach. As indicated by Robert Andrew, the company learned more about the case from the media than the media did from Johnson \& Johnson in the first instance.

\footnotetext{
${ }^{2}$ Baker, Mallen. (2011). The Tylenol case is an extract from Mallen Baker (2011), cited Feb. 9, 2011, www.mallenbaker.net/csr/crisis02/hmt
} 
Johnson \& Johnson's chairman, James Burke, reacted to the negative media coverage by forming a sevenmember strategy team. The team's strategy guidance from Burke was first, "How do we protect the people?" and second, "How do we save this product?" The company's first actions were to immediately alert consumers across the nation, via the media, not to consume any type of Tylenol product. They told consumers not to resume using the product until the extent of the tampering could be determined. Johnson \& Johnson, along with stopping the production and advertising of Tylenol, withdrew all Tylenol capsules from the store shelves in Chicago and the surrounding area. After finding two more contaminated bottles, they realized the vulnerability of the product and ordered a national withdrawal of every capsule (Broom, 1994). Johnson \& Johnson recognized the need to understand the cause of the variation, or new reality, before coming up with solutions.

By withdrawing all Tylenol, even though there was little chance of discovering more cyanide-laced tablets, Johnson \& Johnson showed that they were not willing to take a risk with the public's safety, even if it cost the company millions of dollars. Johnson \& Johnson put the customer first, not figures. The end result was the public viewing Tylenol as the unfortunate victim of a malicious crime (Broom, 1994).

Johnson \& Johnson also used the media - both PR and paid advertising - to communicate their strategy during the crisis, thus emphasizing the need to provide information and communicate in situations of new realities. Johnson \& Johnson used the media to issue a national alert to tell the public not to use the Tylenol product. Before the crisis, Johnson \& Johnson had not actively sought press coverage, but as a company in crisis, they recognized the benefits of open communications in clearly disseminating warnings to the public as well as the company's stand (Broom, 1994, and Fink, 1986). Johnson \& Johnson communicated their new triple safety seal packaging- a glued box, a plastic sear over the neck of the bottle, and a foil seal over the mouth of the bottle - with a press conference at the manufacturer's headquarters. Tylenol became the first product in the industry to use the new tamper-resistant packaging just six months after the crisis occurred (Berge, 1990).

Scholars have come to recognize Johnson \& Johnson's handling of the Tylenol crisis as an example for success when confronted with a threat to an organization's existence. Berge lauds the case in the following manner: "The Tylenol crisis is, without a doubt, the most exemplary case ever known in the history of crisis communications. Any business executive, who has ever stumbled into a public relations ambush, ought to appreciate the way Johnson \& Johnson responded to the Tylenol poisonings. They have effectively demonstrated how major business has to handle a disaster." (pg. 19, 1990)

Johnson \& Johnson employed a forgiveness-and-sympathy strategy for this crisis. Forgiveness strategy seeks to win forgiveness from the public and creates acceptance for the crisis. Here, Johnson \& Johnson did not focus on the blame game or looking for scapegoats, but rather sought after people's cooperation and understanding. Corrective action led to the innovation to prevent a recurrence of the crisis in the future. This intervention was possible after a clear understanding of the cause of the variation. The Johnson \& Johnson Tylenol crisis is an example of how an organization should communicate with the public during a crisis and also seek cooperation. The organization's leadership set the example from the beginning by making public safety the organization's number one concern. This typified a focus on the customer, which is particularity important given the fact that Johnson \& Johnson's main mission with Tylenol is to enhance the public's well-being or heath.

The features that made Johnson \& Johnson's handling of the crisis a success are:

- $\quad$ They acted quickly but reflectively, with complete openness about what had happened, and immediately sought to remove any source of danger based on the worst case scenario - not waiting for evidence to see whether the contamination might be more widespread, though with an understanding of the cause. It must be noted that the managers of Johnson \& Johnson had facts and some understanding about the cause of the problem before acting; what they did not have were figures about how widespread the damage could be.

- Having acted quickly, they then sought to ensure that measures were taken which would prevent, as far as possible, a recurrence of the problem. Without an understanding of the root cause of problems, a possible preventive mechanism to prevent re-occurrence would not have been possible.

- They showed themselves to be prepared to bear the short-term cost in the name of consumer safety. That, more than anything else, established a basis for trust with their customers. This focus on the customer was 
what won the situation for Johnson \& Johnson. Management led by showing the way to go by coming up with the options and selling the idea of a recall to members. The result enhanced public confidence and product innovation in respect of tamper-proof sealing for Johnson \& Johnson, though some were initially concerned about cost implications of the recall process.

Planning

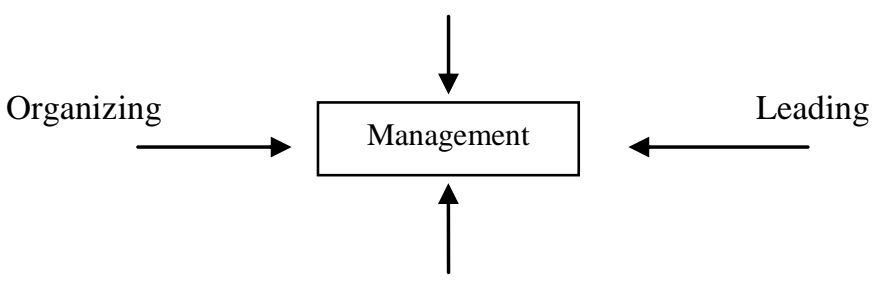

Controlling

Figure 1: Traditional Functions for Ordinary Management

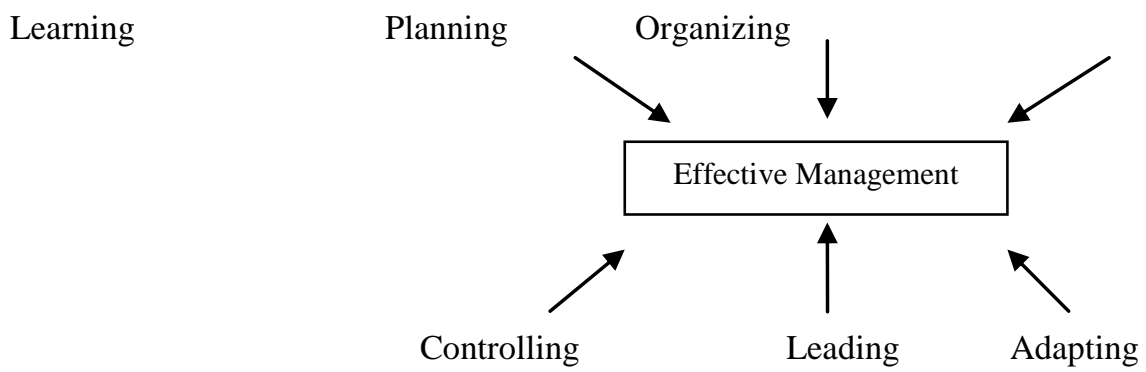

Figure 2: Proposed Functions for Learning-based Management

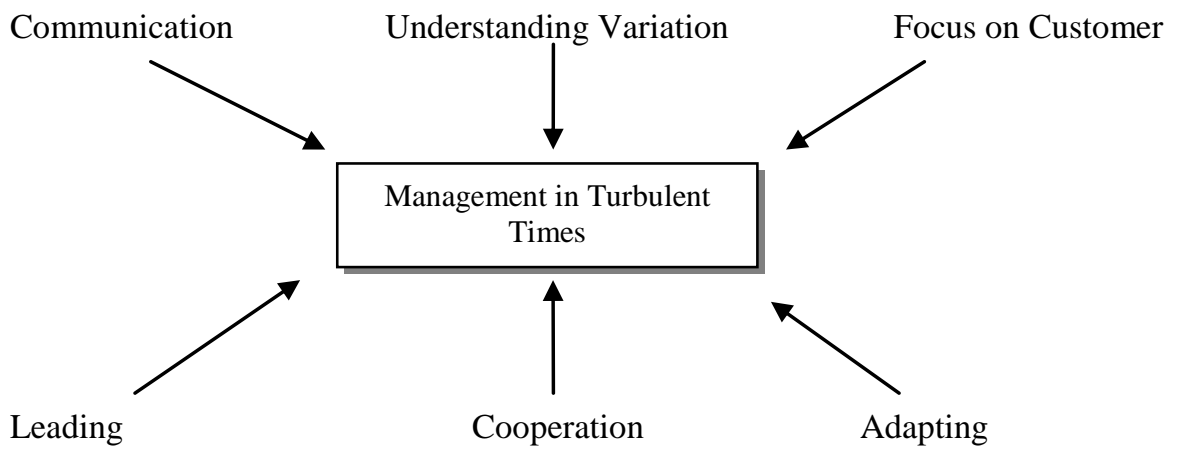

Figure 3: Proposed Concepts for Managing in Turbulent Times

\section{CONCLUSION}

An analysis of the Tylenol case reflects the wisdom in Deming's views in using his classical System of Profound Knowledge to manage in turbulent times. The concept of systems thinking, understanding of variation, learning, and adapting quickly, require flexibility in strategy deployment and putting the customer first in turbulent times. The need to lead using psychology and the theory of knowledge to manage in turbulent times, which could help turn obstacles into opportunities, are well reflected in the Tylenol case. 
Upon reflecting on the views of Deming and Dewey on the theory of Knowledge, it becomes clear that knowledge indeed has a temporal spread and whatever is known at any given time cannot provide full assurance about a fact or truth, or the certainty of what is known, and therefore predict what is likely to happen or not happen. An entity whose sole goal is to avoid errors will quite naturally be a total skeptic and assert nothing. The question then is not what propositions are certain, but what propositions might be preferable as a basis for our actions. It also becomes clear that the aim of a manager is to optimize the system; but when in crisis, the manager should get out of the crisis with minimized harm. The systems of profound knowledge proposed by Deming then become imperative. However, the system cannot be optimized without an understanding of variation and the skill to minimize the effects of uncertainties or new realities. Bearing in mind that what is known is limited by the "knowable" the unknowable and the unknown, managing in turbulent times would require a shift from the sole reliance on specific contemporary management styles to the "Learning Based Management Approach". The Learning Based Management approach (LBM) combines all aspects of the contemporary management approaches, but with an emphasis on learning and adaptation of systems. It also focuses on establishing leadership at all levels to empower people to act without so much fear of uncertainty or mistakes. The following are a few concepts derived from Deming's System of Profound Knowledge to bear in mind during turbulent times or times when managers are faced with new realities.

- $\quad$ The system cannot be optimized without an understanding of variation and uncertainties.

- $\quad$ To optimize opportunities and minimize risk of uncertainty, strategic leaders should adapt a "Learning Based Management (LBM) Approach" which requires flexibility in strategy deployment and an understanding that life is variation.

- $\quad$ The need to focus on the customer first in turbulent times - not on figures.

- $\quad$ The culture of adaptation and cooperation can provide insurance for an organization against uncertainties and sudden shocks from the external environment and minimize the effects of such uncertainties on the organization.

- $\quad$ The culture of learning can provide empowerment, improve competence and commitment, reduce selfblaming, and enhance confidence in strategic leadership decision, while helping to reduce potential internal and external conflicts and subsequently cooperation.

\section{AUTHOR INFORMATION}

Dr. Goski Alabi is a Senior Lecturer in Management and Dean, School of Research and Graduate Studies Institute of Professional Studies, Ghana. She received her Doctor of Business Administration (DBA) from the Swiss Management Centre University and a consultant in Total Quality Management. Goski is also a Chartered Quality Professional of the Chartered Quality Institute (UK) with (CQP, MCQI). Goski is a Quality Management Consultant and was the Lead Facilitator for the National Quality Awareness Workshops in Ghana, consulting for the Ministry of Trade and Industry. She is also a framework consultant and certified Member of the Europe - Africa- Caribbean Liaison Committee (COLEACP) Inter Professional Association on the Pesticides Initiative Program (PIP) as a Service Provider for Good Company Practices working with Fruits and Vegetable exporters in Ghana. E-mail: goskia@yahoo.com

\section{REFERENCES}

1. $\quad$ Ackoff, Russell L. (2010) Systems Thinking for Curious Managers. (Triarchy Press). ISBN 978-09562631-5-5.

2. Argyris, C. and Schön, D. (1996) Organizational learning II: Theory, method and practice, Reading, Mass: Addison Wesley.

3. Baker, Mallen. (2011). The Tylenol case is an extract from Mallen Baker (2011), cited Feb. 9, 2011, www.mallenbaker.net/csr/crisis02/hmt.

4. Barton, L. (1993) Crisis in organizations: Managing and communicating in the heat of chaos. Cincinnati, Ohio: South-Western Publishing Company.

5. Beaver, W. \& Parker, G. (1995) Risk Management Problems and Solutions, McGraw - Hill, New York.

6. Caroll, Lewis, (1872), "Through the Looking Glass and what Alice found There', Lewis Caroll, (1898), "Alice adventure in Wonderland'. 
7. Covey, S (1989), the seven Habits of highly effective people Covey, s. (2004), The $8^{\text {th }}$ Habit From

Effectiveness to Greatness.

8. Darling, John R., (1994) "Crisis Management in International Business: Keys to Effective Decision Making", Leadership \& Organization Development Journal, Vol. 15 Iss: 8, pp.3 - 8.

9. Deming, Edward, 1994, The New Economics for Industry, Government and education, ${ }^{\text {nd }}$ Edition, the MIT press Cambridge Massachusetts, pp. 92-113.

10. Dewey, John. 1930, The Quest for Certainty: A Study of the Relation of Knowledge and Action. London: George Allen \& Unwin.

11. Doyle, Michele Erina and Mark K. Smith. Cited $9^{\text {th }}$ Feb., 2011. Retrieved from www.infed.org/leadership/traditional /leadership.

12. Drucker, P. (1977) Management, London: Pan. Easterby-Smith, M. and Araujo, L. 'Current debates and opportunities' in M. Easterby-Smith, L. Araujo and J. Burgoyne (eds.) Organizational Learning and the Learning Organization, London: Sage.

13. Drucker, P., (1993), Managing in Turbulent Times, Harper, Collins, New-York, pp. 1-10.

14. Fearn-Banks, K. (1996). Crisis communications: A casebook approach. Mahwah, N.J: Lawrence Erlbaum Associates.

15. Fink, S. (1986). Crisis management: Planning for the inevitable. New York, N.Y: American Management Association.

16. Hoffer, Eric. (n.d.). 1-Love-Quotes.com. Retrieved Sun Jul 10 01:13:53 2011, from 1-Love-Quotes.com Website: http://www.1-love-quotes.com/quote/883193.

17. Holmes, A., (2007), turnaround specialist, Mckensy Quarterly, No. 2, pg. 4.

18. Howell, G., \& Miller, R. (2006). How the relationship between the crisis life cycle and mass media content can better inform crisis communication. PRism 4 (1). Available at: http://praxis.massey.ac.nz/prism_online_journ.html.

19. Martinez, Stein G. (2008). Drucker: Classic Advisor of Managing In Turbulent Times, Gestión 2000, Spain.

20. $\quad$ Meredith, Jack (1993) "Theory Building through Conceptual Methods", International Journal of Operations \& Production Management, Vol. 13 Iss: 5, pp.3 - 11.

21. Mitroff, I. \& Anagnos, G. (2001). Crisis in crisis management. Corporate Counsel 8(2), 58.

22. Mitroff, I. I. (1996). Essential guide to managing corporate crisis: A step-by-step guide. New York: Oxford University Press.

23. Mitroff, I., Pauchant, T., \& Shrivastava, P. (1989, February). Crisis, disaster, catastrophe: Are you ready? Security Management: 101108.

24. Nolan and Provost (1990): Understanding Variation, Quality Progress.

25. Pauchant, T. \& Nf Mitroff, 1. (1992). Transforming the crisis prone organization. San Francisco, josseyBass.

26. Pearson, C. \& Clair, J. (1998). Reframing crisis management. Academy of Management Review 23 (1): 5976.

27. Pearson, C. \& Mitroff, I. (1993). From crisis prone to crisis prepared: A framework for crisis management. Academy of Management Executive 71: 48-59.

28. Penrose, J. (2000). The role of perception in crisis planning. Public Relations Review 26 (2): 155.

29. Senge, P. M. (1990) The Fifth Discipline. The art and practice of the learning organization, London: Random House. 424 + viii pages.

30. Spillan, John E, Crandall (2002), William Crisis planning in the nonprofit sector: Should we plan for something bad if it may not occur? http://findarticles.com/p/articles/mi_qa3972/is_200204/ai_n9059230/.

31. Storberg-Walker, J. and Chermack, T. J. (2007). Four methods for completing the conceptual development phase of applied theory building research in HRD. Human Resource Development Quarterly, 18: 499-524. doi: 10.1002/hrdq.1217.

32. Storberg-Walker, Julia, Thomas J. Chermack (2007), Four methods for completing the conceptual development phase of applied theory building research in HRD, Human resource development Journal, Volume 18. No. 4, pp.499-524. Article first published online: 30 Nov.

33. Warwick, M. (1993). Disaster recovery: Come hell or high water. Communication International 20 (10): 33-40.

34. $\quad$ www.harpercollins.com/.../Managing-Turbulent-Times-Peter-F-Drucker/?... - Cached, Cited Feb. 9, 2011. 
\begin{tabular}{ll} 
International Journal of Management \& Information Systems - First Quarter $2012 \quad$ Volume 16, Number 1 \\
\hline
\end{tabular} NOTES 